\title{
Educating physicians in seventeenth-century England - ADDENDUM
}

\author{
Jonathan Barry \\ University of Exeter \\ E-mail: J.Barry@exeter.ac.uk
}

The original version of this paper omitted elements in the Abstract. The full Abstract is as follows:

\begin{abstract}
Argument
The tension between theoretical and practical knowledge was particularly problematic for trainee physicians. Unlike civic apprenticeships in surgery and pharmacy, in early modern England there was no standard procedure for obtaining education in the practical aspects of the physician's role, a very uncertain process of certification, and little regulation to ensure a suitable reward for their educational investment. For all the emphasis on academic learning and international travel, the majority of provincial physicians returned to practice in their home area, because establishing a practice owed more to networks of kinship, patronage and credit than to formal qualifications. Only when (and where) practitioners had to rely solely on their professional qualification to establish their status as young practitioners that the community could trust would proposals to reform medical education, such as those put forward to address a crisis of medicine in Restoration London, which are examined here, be converted into national regulation of medical education in the early nineteenth century, although these proposals prefigured many informal developments in medical training in the eighteenth century.
\end{abstract}

The Publisher apologises for this omission.

\section{Reference:}

Barry, Jonathan. 2019. "Educating physicians in seventeenth-century England," Science in Context 32:137-154. doi:10.1017/ S0269889719000188

Cite this article: Barry, Jonathan. 2019. "Educating Physicians in Seventeenth-Century England - ADDENDUM," Science in Context 32:353. doi:10.1017/S026988971900022X

(C) The Author(s) 2019. This is an Open Access article, distributed under the terms of the Creative Commons Attribution licence (http:// creativecommons.org/licenses/by/4.0/), which permits unrestricted re-use, distribution, and reproduction in any medium, provided the original work is properly cited. 